\title{
Automated Monitoring System for Waste Disposal Sites and Groundwater
}

\section{Accelerated Site Technology Deployment Project NV02SS20}

\section{Project Report}

Prepared by

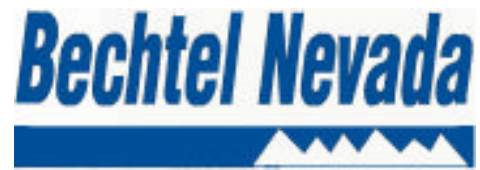

Prepared for

U.S. Department of Energy

National Nuclear Security Administration

Nevada Site Office

under Contract No. DE-AC08-96NV11718

September 2002

(Revised March 2003) 


\title{
DISCLAIMER NOTICE
}

Reference herein to any specific commercial product, process, or service by trade name, trade mark, manufacturer, or otherwise does not necessarily constitute or imply its endorsement, recommendation, or favoring by the United States Government or any agency thereof or its contractors or subcontractors.

Available for sale to the public, in paper, from:

\author{
U.S. Department of Commerce \\ National Technical Information Service \\ 5285 Port Royal Road \\ Springfield, VA 22161 \\ Phone: (800) 553-6847 \\ Fax: (703) 605-6900 \\ E-mail: orders@ntis.fedworld.gov \\ Online Ordering: http://www.ntis.gov/ordering.htm
}

Available electronically at http://www.doe.gov/bridge

Available for a processing fee to the U.S. Department of Energy and its contractors, in paper, from:

U.S. Department of Energy

Office of Scientific and Technical Information

P.O. Box 62

Oak Ridge, TN 37831-0062

Phone: (865) 576-8401

Fax: (865) 576-5728

E-mail: reports@adonis.osti.gov 


\section{CONTENTS}

Acronyms and Abbreviations $\ldots \ldots \ldots \ldots \ldots \ldots \ldots \ldots \ldots \ldots \ldots \ldots \ldots \ldots \ldots \ldots \ldots \ldots \ldots \ldots$

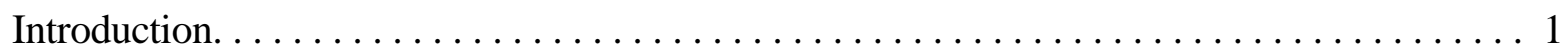

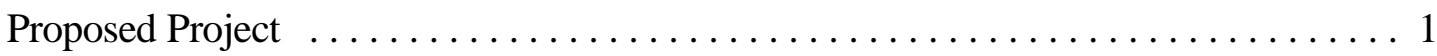

Reporting and Termination........................... 1

Objectives in Original Proposal $\ldots \ldots \ldots \ldots \ldots \ldots \ldots \ldots \ldots \ldots \ldots \ldots \ldots \ldots \ldots$

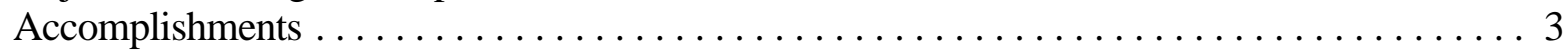

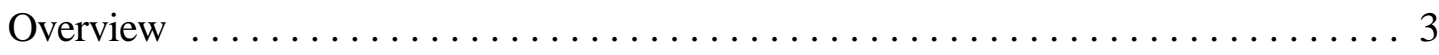

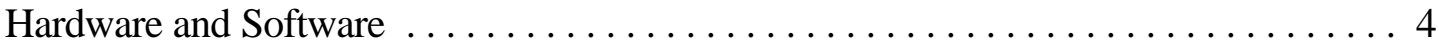

Cellular Modem Systems ... . . . . . . . . . . . . . . . . . . . . 4

Computer Hardware and Software . . . . . . . . . . . . . . . . . 4

Completed FY 2002 Milestones . . . . . . . . . . . . . . . . . 6

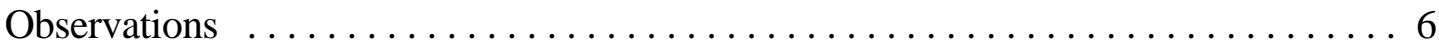

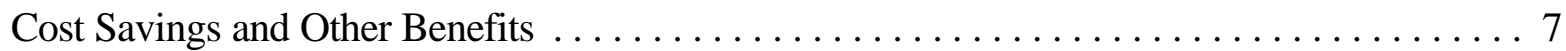

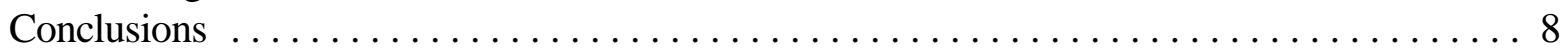

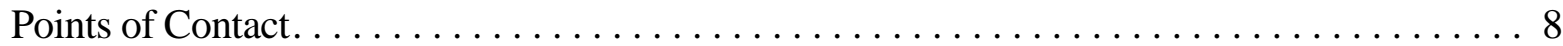

\section{Tables}

Table $1 \quad$ Cellular Modem Deployment ...................... 5

Table 2 Telemetry Data Processing and Abstraction Layer Deployment . . . . . . . 5 


\section{ACRONYMS and ABBREVIATIONS}

$\begin{array}{ll}\text { AMSI } & \text { Advanced Monitoring Systems Initiative } \\ \text { ASTD } & \text { Accelerated Site Technology Deployment } \\ \text { BN } & \text { Bechtel Nevada } \\ \text { DOE } & \text { U.S. Department of Energy } \\ \text { DRI } & \text { Desert Research Institute } \\ \text { ETS } & \text { Environmental Technical Services } \\ \text { FY } & \text { fiscal year } \\ \text { GOES } & \text { Geostationary Operational Environmental Satellite } \\ \text { LANL } & \text { Los Alamos National Laboratory } \\ \text { NTS } & \text { Nevada Test Site } \\ \text { SNL } & \text { Sandia National Laboratories } \\ \text { TDP } & \text { Telemetry Data Processing } \\ \text { TDR } & \text { Time-Domain Reflectometer } \\ \text { WRCC } & \text { Western Regional Climate Center (DRI) }\end{array}$




\section{INTRODUCTION}

\section{Proposed Project}

A proposal submitted to the U.S. Department of Energy (DOE), Office of Science and Technology, Accelerated Site Technology Deployment (ASTD) program to deploy an automated monitoring system for waste disposal sites and groundwater, herein referred to as the "Automated Monitoring System," was funded in fiscal year (FY) 2002. This two-year project included three parts: (1) deployment of cellular telephone modems on existing dataloggers, (2) development of a data management system, and (3) development of Internet accessibility.

The proposed concept was initially (in FY 2002) to deploy cellular telephone modems on existing dataloggers and partially develop the data management system at the Nevada Test Site (NTS). This initial effort included both Bechtel Nevada (BN) and the Desert Research Institute (DRI).

The following year (FY 2003), cellular modems were to be similarly deployed at Sandia National Laboratories (SNL) and Los Alamos National Laboratory (LANL), and the early data management system developed at the NTS was to be brought to those locations for site-specific development and use. Also in FY 2003, additional site-specific development of the complete system was to be conducted at the NTS. To complete the project, certain data, depending on site-specific conditions or restrictions involving distribution of data, were to made available through the Internet via the DRI/Western Region Climate Center (WRCC) WEABASE platform. If the complete project had been implemented, the system schematic would have looked like the figure on the following page.

\section{Reporting and Termination}

Project activities for the initial phase of work at the NTS were completed and are reported in this Project Report. However, funding for FY 2003 was not received from the ASTD Program, so FY 2003 activities were not performed.

BN will continue to complete the NTS-related work, but at a much reduced pace, using its own operational funds.

A completely automated, Internet-accessible monitoring system with an integrated sensor suite was demonstrated at the NTS in 2001 under the Advanced Monitoring Systems Initiative (AMSI). The continuing project will leverage the experience of that initiative to develop a comprehensive unattended monitoring system. The completed system is expected to be a model for many other DOE sites requiring active long-term surveillance.

\section{OBJ ECTIVES IN ORIGINAL PROPOSAL}

\section{Early Detection of Contamination}

A key value of automating a process is providing for the constant monitoring and evaluation of information for surety. The DRI/WRCC WEABASE platform is an existing, mature, and stable platform offering many options and advantages required for this task. It can provide the functionality for early detection of contamination. Because $\mathrm{BN}$ is leveraging the work being 


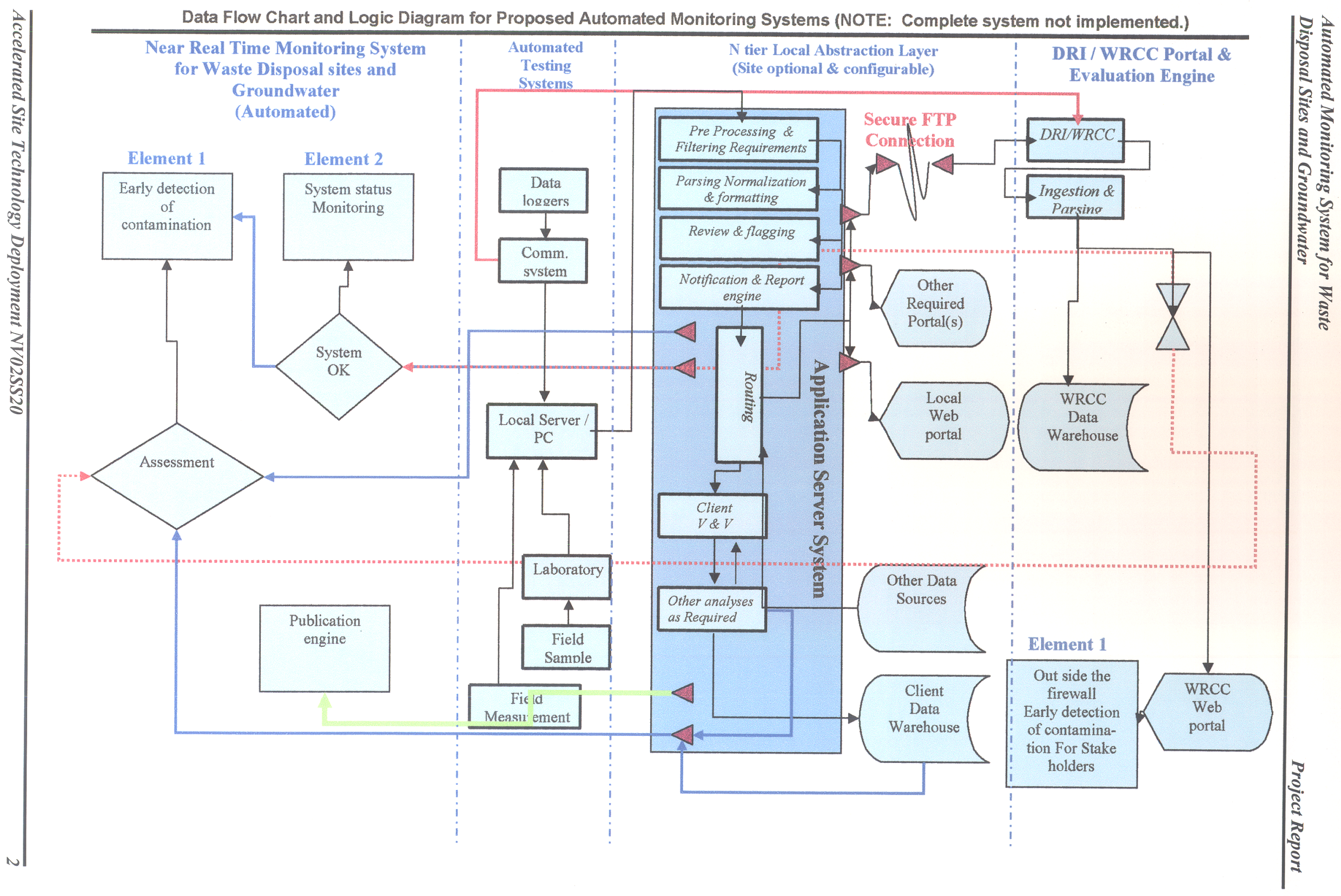


done on other projects such as AMSI and ongoing projects at BN Environmental Te chnical Services (ETS) department, the abstraction layer may contain some functionality provided by WEABASE for ASTD but required locally for other functions.

\section{Automation of Data Collection}

The typical site that will utilize the "Near Rear Time Monitoring System" will have Campbell Scientific hardware and sensors. It is necessary to assure that hardware that is not manufactured by Campbell Scientific will work with the automated data collection process and that it be easily adaptable to forthcoming technologies.

\section{Exportable System for DOE-Wide Application}

A system that is designed to be deployed to as many as 60 sites must be flexible. To address this, the "Near Rea-Time Monitoring System" is deployable in two versions.

One utilizes the automated hardware platform (this is common to all systems) and the DRI/WRCC WEABASE platform exclusively. This configuration is perfectly suited to sites that have a minimum of site-specific requirements and mainly utilize data from the automated hardware platform.

For clients having site-specific requirements that go beyond the scope of what can reasonably be accommodated with a single-tier offering of the "Near RealTime Monitoring System," there is an "N" tier version.

The "N" tier Abstraction Layer will be developed utilizing Microsoft Office Professional and Visual Basic.Net. It is imperative that the best tools and methods be used. The technology sector has begun to shift toward using the Microsoft.Net framework. When properly implemented, the .Net paradigm will provide users with access to their data and applications anywhere and anytime without having to be aware of where the software resides or what platform it is running on. Utilizing the .Net frameworks will result in a completely open source application. The entire uncompiled source code will be delivered with the " $\mathrm{N}$ " tier version of the "Near Real Time Monitoring System."

This configuration is suited to sites that have site-specific requirements and may utilize data from numerous sources in addition to the automated hardware platform. Each site can leverage the basic system to resolve local requirements or restrictions.

The development platform for the " $\mathrm{N}$ " tier version will be kept as simple as possible, utilizing only commonly available COTS (completely off the shelf) development tools.

\section{ACCOMPLISHMENTS}

\section{Overview}

The activities summarized below were accomplished in FY 2002. More detail is contained in the following sections of the report. 
A plan for the Automated Monitoring System was worked out as a collaborative plan with BN and DRI. As funding for environmental monitoring becomes harder to obtain, it is important that partnerships be established as was done for this ASTD project.

All initially planned cellular telephone modems have been installed and tested. Seven systems were deployed by BN and two more are expected to be installed by BN for DRI. In addition, all of the existing remote locations that were serviced by hard telephone line have switched over to Tier 1 of the Telemetry Data Processing (TDP).

The server purchased to support this project has been configured and placed online with SQL 2000, Microsoft.NET's development environment and IIS web service.

The design for the TDP and Abstraction Layer has been completed and the Implementation Plan was published. Tier 1 of the TDP, which consists of a dialout server and Campbell LoggerNet software configured for NTS application, is completed and on line. The Alpha version of the TDP is 75 percent complete. Work has started on several of the Beta-version modules.

\section{DEFINITION OF ALPHA VERSION \\ A functional or partly functional program that is the first assembled code released for testing, demonstration, or showing off an idea for a product. Even though it may look like a finished product, an Alpha version is not meant to be utilized outside the development team. Its code is flawed, error-prone, lacks complete code quality testing, and will suffer from stability problems. An Alpha version may require copious effort before it is considered releasable.}

\section{DEFINITION OF B ETA VERSION}

A functional or partly functional program that is the first version considered releasable to clients for testing. Beta versions should contain nearly all the functionality required by the finished product and have a completed or nearly completed user interface. While a Beta version is not meant to be utilized for production, it should be tested by the end users in a production environment. Its code may contain some flaws, have some errors, and have minor stability problems.

DRI worked with SNL to create an N-tier abstraction layer with WEABASE. It was demonstrated as part of a sensor failure mode analysis with SNL.

\section{Hardware and Software}

\section{Cellular Modem Systems}

Seven cellular systems were deployed at the NTS locations, and include the sensors listed in Table 1.

\section{Computer Hardware and Software}

The BN computer hardware and software configurations for this first and only year of the project are detailed in Table 2. 
Table 1. Cellular Modem Deployment.

\begin{tabular}{|l|l|l|}
\hline \multicolumn{1}{|c|}{ Location } & \multicolumn{1}{|c|}{ Sensors } & \multicolumn{1}{c|}{ Status } \\
\hline Pilot Well-2 & Transducer(s) & Installed \\
\hline Pilot Well-3 & Transducer(s) & Installed (Failed) \\
\hline Area 5 Lysimeter North & $\begin{array}{l}\text { Load Cell and } \\
\text { tipping bucket }\end{array}$ & Installed \\
\hline Area 5 Lysimeter South & $\begin{array}{l}\text { Load Cell and } \\
\text { tipping bucket }\end{array}$ & Installed \\
\hline Pit 5 North & $\begin{array}{l}\text { Time-Domain } \\
\text { Reflectometers } \\
\text { (TDR[s]) }\end{array}$ & Installed \\
\hline Pit 5 South & TDR(s) & Installed \\
\hline Area 3 Flume & $\begin{array}{l}\text { Transducer(s) and } \\
\text { tipping bucket }\end{array}$ & Installed \\
\hline Area 5 Flume & $\begin{array}{l}\text { Transducer(s) and } \\
\text { tipping bucket }\end{array}$ & Phase II \\
\hline & & Installed \\
\hline U-3bw Crater & Met tower &
\end{tabular}

Table 2. Telemetry Data Processing and Abstraction Layer Deployment.

\begin{tabular}{|l|l|}
\hline \multicolumn{1}{|c|}{ Component } & Status \\
\hline Server hardware (NTS) & \\
\hline MS 2000 Server operating system & Online and Tested \\
\hline MS SQL 2000 & Online and Tested \\
\hline MS IIS Web service & Online and Tested \\
\hline MS .Net Frame Works & Online and Tested \\
\hline Backup to DVD burner & Online and Tested \\
\hline & Online and Tested \\
\hline First-tier hardware & \\
\hline PC workstation & \\
\hline Campbell LoggerNet software & Online and Tested \\
\hline Campbell RTDM software & Online and Tested \\
\hline & Online and Tested \\
\hline
\end{tabular}


Table 2 (continued)

\begin{tabular}{|c|l|}
\hline \multicolumn{1}{|c|}{ Component } & \multicolumn{1}{c|}{ Status } \\
\hline Abstraction Layer & Alpha level \\
\hline OLTP layer & \\
\hline Job Scheduling & Alpha level \\
\hline Data Parsing & Alpha level \\
\hline Database Manipulation & Alpha level \\
\hline Data Publication & Alpha level \\
\hline Statistical Analysis & To be implemented \\
\hline Real-time Email Alert Daemon & To be implemented \\
\hline & \\
\hline Intranet Interface & Beta released \\
\hline User interface & Beta level \\
\hline Connection to data bases & Beta level \\
\hline Data Base Layer & Beta level \\
\hline
\end{tabular}

\section{Completed FY 2002 Milestones}

- BN/DRI plan for Automated Monitoring Systems for Waste Disposal Sites and Groundwater project

- Telemetry Data Processing and Abstraction Layer Implementation Plan

- Server to support ASTD at the NTS configured and placed on line

- Telemetry Data Processing and Abstraction Layer Implementation Plan

- All Cellular Telephone Modems installed and tested

- Backup system in place

- Installed Microsoft's .Net Frameworks

- Completed training on Microsoft's .Net Frameworks

- Released Beta version of the Telemetry Data Processing and Abstraction Layer

\section{Observations}

- Early in the design of the Automated Monitoring System, it was determined that a "One Size Fits All" approach was not practical. Many potential customers have limitations that require local restrictions or constraints be administered prior to data being released from their exclusive control. Some of these restrictions were "self-imposed requirements," some "contractual obligations," and others "security issues." The solution was to broaden the project concept to a modular process with graded implementation. There are three modules: (1) telemetry/field logger hardware, (2) N-tier abstraction layer, and (3) DRI/WRCC WEABASE platform. The simplest system consists of modules 1 and 3. For clients with local restrictions, some or all of the functionality of module 2 is added. The unattended and automated review and analysis of data is fully implemented, regardless of which implementation is deployed.

- In the initial work scope, there is an assumption that every site will maintain site-specific data storage for archiving. In designing a system for wide distribution, it is not practical to 
make this assumption. The scope of the DRI/WRCC WEABASE platform could be expanded to support long-term archiving for sites that require this option.

- At least one telemetry location is beyond the range of the local cellular telephone coverage area. A possible solution would be to purchase and install a GOES (Geostationary Operational Environmental Satellite) modem from Campbell Scientific and test GOES as a resource to reach monitoring locations outside of cellular coverage.

\section{COST SAVINGS and OTHER BENEFITS}

At the NTS, deployment in Area 3 and Area 5 entailed automation of data collection from TDRs, heat dissipation probes, lysimeters, thermistor probes, and meterological sensors. The sensors and instruments themselves have been installed and paid for by Radioactive Waste Management Site operations; their costs are not included in the cost-benefit analysis. Only data telemetry, data analysis, verification and validation protocols, and data display were included in the calculations. Overall, the total number of sensors to be automated in Area 3 and Area 5 is 291.

Reducing the cost of remote monitoring continues to be a long-term goal of the BN ETS department at the NTS. Savings opportunities include:

- Eliminating manual data collection by using automated data collection.

- Using a common system at as many as 60 different locations.

- Sharing expertise and experience among the client base.

- Providing a turnkey solution to client sites with few or no site-specific requirements or restrictions.

- Providing a near-turnkey solution to client sites with specific requirements, restrictions, or unique circumstances.

This project has greatly reduced the time it will take to implement the complete automated process. With initially planned cellular modems and Tier 1 of the TDP in place, a reduction in hours required to collect data has been realized.

The need for weekly site visits has been reduced by 75 percent at this stage in the implementation. The spillover benefits such as reduced worker risk, gasoline usage/hydrocarbon emissions, disposal of supplies and personal protective equipment, and the cost incurred by skipped or lost data are similarly reduced. Bechtel Nevada and DRI also created the start of a data management solution that has the feature set and flexibility to be a tool utilized by a wide array of clients.

As the TDP is further implemented, the total sampling cost will continue to decrease with the added benefit of reduced compliance risk and greater stakeholder confidence. Upon completion of the overall project, a three- to fourfold reduction in monitoring costs could be realized at the NTS. The annual cost of the program now is more than $\$ 600,000$. 


\section{CONCLUSIONS}

Reducing the cost and labor required to support data collection and processing for remote monitoring sites has been a long-term goal of BN's ETS department at the NTS. The long-term plan to manage the cost of remote monitoring at the NTS has been advanced by several factors as a result of this project.

- The implementation and enhancement of the cellular telephone towers at the NTS.

- Building on the AMSI project to demonstrate and prove the concept of cellular telephone telemetry.

- This project made it possible to acquire and deploy the hardware on a greatly accelerated schedule.

- This project made it possible to design the data reduction and processing software suite in FY 2002.

\section{POINTS of CONTACT}

Principal Investigator

Stuart Rawlinson

Phone 702/295-1185 E-Mail rawlinse@nv.doe.gov

Scientific Task Lead

Lloyd Desotell

Phone 702/295-1228 E-Mail desotelt@nv.doe.gov

Technical Task Lead

Robert Peppard

Phone 702/295-1848

E-Mail pepparrg@nv.doe.gov

Application Engineer

Michael Belangia

Phone 702/295-2529 E-Mail belangms@nv.doe.gov 


\section{DISTRIBUTION LIST}

U.S. Department of Energy

National Nuclear Security Administration

Nevada Site Office

Technical Library

P.O. Box 98518

Las Vegas, NV 89193-8518

U.S. Department of Ene rgy

National Nuclear Security Administration

Nevada Site Office

Public Reading Facility

P.O. Box 98518

Las Vegas, NV 89193-8518

U.S. Department of Energy

Office of Scientific and Technical Information

P.O. Box 62

Oak Ridge, TN 37831-0062
1 copy

1 copy

1 electronic copy 